public health system in rural areas, a process that acquired speed in the 1980s and galloped towards corporatisation after 2000."

Here, the rapid expansion of private services has been mostly in urban areas. Data is unlikely to show much private expansion in the rural areas. The push to go for higher end treatment is market driven, related to liberalisation rather than to an actual decrease in public facility performance or decrease in performance per unit population.

In 2016, there were 209,010 government beds in rural areas compared to 111,872 in 2005 (90\% increase). In the same period government beds in the urban areas saw only a $45 \%$ increase $(425,869$ in 2016 against 292,813 in 2005) $(4,5)$. So, there have always been more government beds in urban areas than in rural areas even though $69 \%$ population is in rural areas. But only $3 \%$ of the doctor population lives in rural areas (4). Since one third of government beds are in rural areas, and the existence of one third of government beds in rural areas presumably draws $30 \%$ government doctors to rural work, we can assume that $7 \%$ of doctors are government employees working in urban areas. It seems that the overwhelming majority of all doctors is in the urban private sector.

\section{References}

1. Jain Y, Patil SB, Phutke GB. Sustaining for-profit emergency healthcare services in low resource areas. Indian J Med Ethics. 2018 Oct-Dec;3(4) NS:334-6. DOI:10.20529/JME.2018.062. Available from: http://ijme.in/ articles/sustaining-for-profit-emergency-healthcare-services-in-lowresource-areas/.

2. Bawaskar HS, Bawaskar PH.Emergency care in rural settings: Can doctors be ethical and survive? Indian J Med Ethics. 2018 Oct-Dec;3(4):329-30. DOI: 10.20529/IJME.2018.038 . Available from: http://ijme.in/articles/ emergency-care-in-rural-settings-can-doctors-be-ethical-andsurvive/?galley $=$ html

3. Chiriac M. Romania raises medics'salaries to stem exodus. Balkan Insight. 2014 Jul 23. Available from: http://www.balkaninsight.com/en/article/ romania-plans-raising-salaries-for-health-professionals

4. Central Bureau of Health Intelligence. National Health Profile of India 2017. New Delhi: Directorate General of Health Services, MoHFW; 2017. Available from: http://www.cbhidghs.nic.in/index1.php?lang=1\&level= 2\&sublinkid $=87 \&$ lid $=1137$

5. Central Bureau of Health Intelligence. National Health Profile of India 2005. New Delhi: Directorate General of Health Services, MoHFW; 2005. Available from: http://cbhidghs.nic.in/index1.php?lang=1\&level=2\&su blinkid $=77 \&$ lid $=83$

\title{
Authors' response to commentaries on "Emergency care in rural settings"
}

\author{
HIMMATRAO SALUBA BAWASKAR, PRAMODINI HIMMATRAO BAWASKAR
}

We are grateful to Kattula (1) and Jain, Patil and Phutke (2) for their comments on our article on rural emergency medical care and our real problems in rural practice, their management and the threat to our survival (3). We agree with most of their points and the solutions they have advocated $(1,2)$.

However, since the medical profession has come under the purview of The Consumer Protection Act, 1986, fear of the hanging sword of the law has caused doctors constant stress, while their dedicated practice and interest in research are no longer of any value. To avoid legal liability, doctors are obliged to order several pathology investigations and expert opinions, which makes patients feel they are only profit-oriented, a belief

Authors: Himmatrao Saluba Bawaskar (himmatbawaskar@rediffmail.com) Bawaskar Hospital and Clinical Research Centre, Mahad, Raigad 402 301, INDIA; Pramodini Himmatrao Bawaskar (pramodinibawaskar@gmail.com), Bawaskar Hospital and Clinical Research Centre, Mahad, Raigad 402 301, INDIA.

To cite: Bawaskar HS, Bawaskar PH. Authors' response to commentaries on "Emergency care in rural settings" Indian J Med Ethics. 2018 Oct-Dec;3(4) NS:337.DOI:10.20529/IJME.2018.090.

( ) Indian Journal of Medical Ethics 2018 shared by the authors of the second commentary (2). They are not aware of what it costs to run a private hospital while providing ethical care. We have stood firm against industry sponsorship of doctors' participation in conferences and repeatedly fought against cut practice (4).

Today, rural government hospitals are often just buildings, with inadequate qualified staff including medical officers, and inadequate infrastructure. It is inevitable that the rural people are forced to depend on private healthcare. In this situation, unless there is universal health insurance for all, there will be no space left for the rural private healthcare providers.

\section{References}

1. Kattula D. Emergency care in rural settings: no easy solutions. Indian J Med Ethics. 2018 Oct-Dec;3(4) NS:331-3. DOI:10.20529/JMME.2018.059.

2. Jain Y, Patil SB, Phutke GB. Sustaining for-profit emergency healthcare services in low resource areas Indian J Med Ethics. 2018 Oct-Dec;3(4) NS:334-6. DOI:10.20529/IJME.2018.062.

3. Bawaskar HS, Bawaskar PH. Emergency care in rural settings: Can doctor be ethical and survive? Indian J Med Ethics. 2018 Oct-Dec;3(4)NS:329-30. DOI: 10.20529/IJME.2018.038.

4. Sachan D Tackling corruption in Indian medicine. Lancet. 2013 Nov 16; 382(9905): e23-4. 